dislocation to move in a definite direction, the external stress $\sigma$ must bo greater than $\sigma_{0}$ at all points along the dislocation. Hence the observed yield point should be of the order of the mean value of $\sigma_{0}$.

There was a discussion of tho mechanism of precipitation of one phase from another, and of the cause of precipitation hardening. Prof. $R$. Becker emphasized that in alloys in which the degree of supersaturation is small, the time taken to form a nucleus will be long, because a small nucleus will be unstable owing to surface tension, and will usually evaporate before it can grow to a size at which it will be stable. Thus on cooling an alloy, the precipitation is not so rapid on first entering the two-phase region as at a lower temperature where the degree of supersaturation will be greater; and this is so in spite of the very rapid drop in the diffusion rate as the temperature is lowered (cf. R. Becker, Ann. Phys., 32,128 ; 1937).

The distinction was emphasized between precipitates which have broken away from the parent lattice and form a new phase, and the smaller nuclei or 'knots' which are formed in the parent lattice, without breaking away. A thermodynamical equilibrium is possiblo between such knots and the original solid solution, and probably oxists in duralumin.

In cases where the two phases have widely differing lattice parameters, it may be impossible for a stable nucleus of one phase to form in the lattice of the other, without breaking away; the energy required to expand or compress the nuclous is too great, so that precipitation would lead to an increase in the free energy. Thus any stable nucleus must already have broken away from the parent lattice. It was suggested, however, that the strain energy would be less if the nuclei assumed a plate-like shape; and that this might be the cause of the segregation of copper atoms on the (100) planes of the aluminium lattice observed by Proston in single crystals of copper aluminium alloys.

Prof. W. L. Bragg described a theory of the structure of a cold-worked metal. The boundaries between the crystallites of a metal must in general be mobile at room temperature; it was. suggested that these boundaries are not frozen in position but are in dynamical equilibrium undor their surface tensions. Thermal fluctuations will cause these boundaries to wave about, and will lead to the gradual disappearance of the smaller crystallites. Thus if a metal is thrown into an amorphous state by cold-working, it will rapidly self-anneal up to a certain coarseness of crystallite size, characteristic of the temperature, beyond which point crystallite growth should be very slow. According to these ideas, no truly amorphous stato is possiblo in a metal.
N. F. II.

\title{
POPULATION PROBLEMS OF HOUSING ESTATES
}

A CHARACTERISTIC of the admirable series of studies issued by the Social Science Department of the University of Liverpool* is their attempt to foresee the problems which social and economic tendencies are presenting to-day and to indicate measures which might be taken either to solve them as they arise or to prevent them becoming too intractable. The latest addition to the New Merseysido Series is no exception. In this survey of the population problems of new estates, with special reference to Norris Green, Mr. Norman Williams indicates the difficulties caused in such districts by a failure in human understanding, together with a serious lack of co-ordination between the different departments of the local authority in the early stages of development. In regard to the provision of schools, for example, the survey reveals grave weaknesses in our present system of local government, an entirely new area with entirely new problems being administered by numerous departments, out of touch with the estate, often acting independently and sometimes in opposition to each other.

The acute problem of school accommodation in Norris Green resulted directly from the policy of the Housing Committee, but it was left to the Education Committeo to solve. Mr. Williams indicates some of the serious consequences of this lack of foresight and co-ordination : the exclusion of children from infants' schools until they were considerably boyond the normal age ; the very frequent transference of pupils from one department to a higher; the unusually large classes (up to fifty-six), first in the junior schools and then in the senior schools. Accompanied by

* University of Liverpool: Social Science Department, Statistics Dirision. Population Problems of New Estates, with Special Reference to Norris Green. Pp. 52. (Liverpool: University Press of Liverpool, 1939.) 18. net. these features has been a steady decline in number of children seoking admission, which has resulted in a steady decrease in the mean age of admission into infants' schools, and it is anticipated that within two or three years sufficient spare room will be available in most infants' schools in Norris Green for the organization of nursery classes.

Mr. Williams, however, is not content with directing attention to the mistakes of the past and the disastrous consequences of lack of accommodation and large classes for a fow children. He is equally concerned with the future. The figures he quotes indicato that the big fall in school population will be accompanied by a big rise in the supply of juvenile labour, and since the local demand for labour shows no signs of increasing, a big increase in unemployment is to be expected amongst boys and girls. It is pointed out that among male adults, unemployment rose from 9 per cent in 1930 to 22 per cent in 1937, the actual increase in numbers being 550. In 1937 there woro about 1,200 unmarried men of more than nineteen in Norris Green, a figure which is expected to increase to 1,500 by 1942 and 2,100 in 1947. The chances of these men obtaining employment are not encouraging and there is the prospect of about 1,400 of them being unemployed in 1942 .

Transport provides another example of a problem created by the Housing Department and left to another Corporation Department to solve. The amount of work in tho locality is limited and the extra workers, if thoy obtain employment, must find it at a distance and will need conveyance. It is doubtful whether the present extended sorvices meet the need, and by 1947 it is possible there will bo an increase of moro than 50 per cent in those using the combined bus and tram services. 
Equally on the question of housing itself, Mr. Williams points to past mistakes and to errors which require correction. In the early stages roads were unmade, there were no shops, several houses were without light; public halls, cinemas, baths, libraries, and welfare centres found no place in the schemes. With few exceptions all the houses in the earlier municipal housing estates have three bedrooms, with the result that there are both empty and overcrowded bedrooms even in the same street. To-day in Norris Green there is little relation between the houses supplied and the accommodation required. There is no suitable accommodation for the majority of ordinary working-class families of seven persons, and none at all for those of more than seven.
Similarly, the absence of accommodation for young couples when they marry is driving them to find accommodation elsewhere. Had the local authority given more attention to the social needs of the people in the early days the number of removals would have beon considerably less.

The study shows conclusively the important con. tribution which the sociologist might make to the rectification of past errors and the prevention of similar mistakes in the future. It is an admirable illustration of the type of study for which there is indeed great need and which might well arrest the attention of scientific workers, as that of the local authorities primarily responsible for the housing estates.

\section{ATMOSPHERIC POLLUTION}

\section{$\mathrm{T}$} HE twenty-fourth report on "Atmospheric Pollution" issued by tho Department of Scientific and Industrial Research appears in a now format and in two volumes, namely, tho report on observations up to March 31, 1938 (H.M. Stationery Office, 2s. net) and the other a supplement giving deposit tables over the same period (H.M. Stationery Office, $4 s .6 d$. net). This arrangement will be a convenience to those who are interested in the general results rather than the actual observations. These show that there has been a tendency for the air to become cleaner. Again Cardiff provides the lowest figure for sooty matter and many will learn -with surprise that the London area provides some of the worst figures. Greenwich had the greatest number of days with heavy smoke haze. Stoke followed next and then Victoria Street, London.

The report contains a section explaining in simple terms how fogs are formed. In Great Britain fogs are said to be caused either by water droplets in the atmosphere or by smoky particles. The water droplets in a fog are only a few thousandths of a millimetre in diameter and for this reason the sun, if visible, appears as a white disk. In a smoko fog, particles are smaller and the sun therefore appears red because the smaller smoke particles scatter light of shorter wave-lengths but not the longer red wavelengths.

It appears essential, the report continues, in the formation of fog that the air should contain very small particles on which the water condenses, for example, sea salt and nitrous and sulphuric acid. The other essential condition for the formation of a water fog is that the temperature of the air must be cold enough for condensation to take place. A high wind may prevent fog. but some wind is essential so that the air can be cooled rapidly.

During condensation fogs, there is usually at a fow hundred feet above the ground a layer where the air is warmer than the air below. On a nearly calm day this layer of warm air forms a kind of lid or ceiling below which fog forms. The formation of this layer is an important link between a smoke fog and a water fog.

Smoke escaping from an ordinary chimney is accompanied by hot gases which carry it upwards and the smoke particles may then meet an upper air current which carries them away. If, however, they reach a layer of air which is as warm or warmer than themselves, they cannot escape through this ceiling. If the ceiling is well above the tops of the chimneys and there is not sufficient wind to carry off the smoke, it collects between the ceiling and the ground; we may then get what is known as a 'high fog' where tho accumulation of smoke occurs in a layer above the house-tops of the city leaving the air in tise streets comparatively clear. Should the level of the ceiling be low enough, smoke accumulation will occur near the ground.

"If," the report states, "we consider the extreme case which might occur, it may make the matter clearer still. Supposing that over a city like London, the wind fails completely up to a height above which the smoke cannot penetrate. The result of this will be that, after a few hours of a winter's day, the city will be covered by a pall of smoke, and this will get darker as the smoke accumulates overhead until the equilibrium is established between the rate at which the smoke particles settle out of the air on to the ground and houses and that at which they are poured from the chimneys. Ultimately, under such conditions the soot fall in the city would be just equal to the soot emitted from the chimneys; but before this condition could be reached, the city would probably bo in complete darkness and life might become practically-impossible, because not only would the smoke accumulate but also other products of combustion, such as carbon dioxide and sulphur dioxide. Wind is therefore of vital importance as the principal scavenger we have to rely upon to protect us from the smoke which we ourselves produce.

"The smoke fog of our large cities is simply a result of failure on the part of the scavenging forces of Nature, which we rely upon to clear away the smoke, as in the past we relied upon our streams and rivers to carry away our sewage.

"So far as condensation or water fogs are concerned, our cities are less likely to suffer from these than the surrounding country. This is due to two main factors, first that the air over tho city is warmer than that in the surrounding country, while the drainage due to the provision for carrying away rain from roofs and streets is such that the ground is very rapidly dried up oven after rain and has little opportunity of contributing to the water content of the air in contact with it."

The time is surely past when we should rely on the chance forces of Nature to scavenge our atmosphere and maintain tolerable urban conditions. 